\title{
Does the type of sedentary behaviors influence blood pressure in adolescents boys and girls? A cross-sectional study
}

\author{
Será que o tipo de comportamento sedentário influencia a pressão \\ arterial em meninos e meninas adolescentes? Um estudo transversal
}

\author{
Luciano Machado Ferreira Tenório de Oliveira ${ }^{1}$ \\ Raphael Mendes Ritti-Dias ${ }^{2}$ \\ Breno Quintella Farah ${ }^{3}$ \\ Diego Giulliano Destro Christofaro ${ }^{4}$ \\ Mauro Virgílio Gomes de Barros ${ }^{1}$ \\ Paula Rejane Beserra Diniz ${ }^{1}$ \\ Fernando José de Sá Pereira Guimarães ${ }^{1}$
}

\footnotetext{
${ }^{1}$ Universidade de

Pernambuco. Av. Gov.

Agamenon Magalhães,

Santo Amaro. 50100-

010 Recife PE Brasil.

luciano2308@hotmail.com

${ }^{2}$ Universidade Nove de

Julho. São Paulo SP Brasil.

${ }^{3}$ Departamento de

Educação Física,

Universidade Federal de

Pernambuco. Recife PE

Brasil.

${ }^{4}$ Laboratório de

Investigação em Exercício,

Departamento de Educação

Física, Universidade

Estadual Paulista. Presidente

Prudente SP Brasil.
}

\begin{abstract}
The aim of this study was to analyze the association between different sedentary behaviors and high blood pressure in adolescent boys and girls. We conducted a cross-sectional study with 6,264 Brazilian adolescents (14 to 19 years old). Demographic data, obesity indicators and blood pressure, were evaluated. Time spent in the sedentary behaviors (television viewing, playing video games, using the computer, non-screen sitting and, total time sitting) were also assessed. The girls spent more time watching television than boys, whereas boys spent more time using computers and video games (12.7\% vs. $7.4 \%, p$ $<0.001)$ than girls. Boys who watched more than four hours of television presented higher odds to give high blood pressure after adjustments for physical activity level, body mass index, age and educational level of mother $(O R=2.27, p<$ 0.001 ). In girls, we did not find a relation between sedentary behaviors and high blood pressure ( $p>$ 0.05 ). Television viewing time is associated with high blood pressure only boys. So, reduce this sedentary behavior, stimulating physical activities, might be essential to health, principally for male adolescents.
\end{abstract}

Key words Sitting time, Screen time, Health behavior, Adolescent, Blood pressure
Resumo O objetivo desta pesquisa foi analisar a associação entre diferentes comportamentos sedentários e pressão arterial elevada em meninos e meninas adolescentes, em estudo transversal com 6.264 adolescentes brasileiros (14 a 19 anos de idade). Foram avaliados dados demográficos, indicadores de obesidade e pressão arterial, assim como o tempo gasto em comportamentos sedentários (assistir televisão, jogar videogame, usar o computador, e o tempo total sentado). As meninas passaram mais tempo vendo televisão do que os meninos, enquanto estes usaram mais computadores e jogos de vídeogame (12,7\% vs. 7,4\%, $p<$ $0,001)$ do que elas. Meninos que assistiram mais de quatro horas de televisão apresentaram maior probabilidade de ter pressão arterial elevada após os ajustes pelo nivel de atividade física, índice de massa corporal, idade e nível de instrução da mãe $(\mathrm{OR}=2,27, p<0,001)$. Com as meninas não foi observada uma relação entre comportamentos sedentários e pressão arterial elevada $(p>0,05)$. O tempo assistindo televisão esteve associado com a pressão arterial elevada apenas entre os meninos. Assim, reduzir o comportamento sedentário, estimulando atividades físicas, pode ser essencial para a saúde, principalmente para adolescentes do sexo masculino.

Palavras-chave Tempo sentado, Tempo de tela, Comportamento de saúde, Adolescentes, Pressão arterial 


\section{Introduction}

High blood pressure (HBP) is a major risk factor for several cardiovascular diseases including coronary artery disease and stroke ${ }^{1}$, affecting between 2.5 and $17.3 \%^{2}$ of adolescents. As HBP is associated with atherosclerosis development in youth ${ }^{3}$. Besides, HBP in childhood was strongly related to increased rates of premature death from endogenous causes in adults".

Formally, sedentary behavior (SB) refers to any waking behavior with low energy expenditure ( $\leq 1.5 \mathrm{METs})$ while in a sitting or reclining posture ${ }^{5}$. Based on this description and epidemiological data, the literature shows that the prevalence of SB is increasing in Brazil and It, probably, is a reflex of technological advances. Currently, $35.7 \%$ of Brazilian adolescents, with more than 14 years old, spend, on average, for 3 hours or more per day, watching television ${ }^{6}$, what characterize the presence of $\mathrm{SB}$ in this population.

Although, overweight and low physical activity level have an association with sedentary behaviors in adolescents ${ }^{7,8}$, the relationships with HBP in this group still controversial. Previous studies showed that screen time ${ }^{5,7}$ was related to HBP in adolescents, while other studies have not observed any significant association between screen time ${ }^{8,9}$. Moreover, other sedentary behaviors as total time sitting or spending in non-screen activities are not explored in the literature ${ }^{10}$.

In fact, SB and prevalence of HBP might have a dependence of $\operatorname{sex}^{11}$. Previous studies ${ }^{12-14}$ have shown that boys are more sedentary than girls, particularly in sitting time to play video games and to use the computer on weekends. About HBP, boys have a higher prevalence than girls ${ }^{15}$.

However, it remains less clear if the association between the sedentary behavior and HBP is also different between sexes. Differences between gender behaviors should be considered, since they can be different associations with $\mathrm{HBP}^{16,17}$. Thus, the aim of this study was to analyze the association between SB and HBP in adolescents.

\section{Material and methods}

\section{Study design and sample}

This study is cross-sectional, approved by The Ethical Committee of The University of Pernambuco in compliance with the Brazilian National Research Ethics System Guidelines. The target population was limited to high school students between 14 and 19 years old. Participants are from the public education system in the State of Pernambuco (Northeast of Brazil), which encompasses approximately $80 \%$ of all students attending this level of schooling.

The following parameters were used to calculate sample size: $95 \%$ of confidence interval; a maximum tolerable error of 2 percentage points; design effect (deff) $=2$; and, because this study comprehended the analysis of multiple risk behaviors and different frequencies of occurrence, the estimated prevalence was $50 \%$. Additionally, to minimize the limitations caused by eventual losses in the application and/or inadequate completion of the questionnaires, it was decided to add $20 \%$ to the sample size.

An attempt was made to ensure that the distribution of students in the sample was balanced concerning the geographical allocation of students, school size and the period of the day that students attended school. The number of students enrolled in each of the 17 school districts, which are political organizations responsible for managing schools belonging to their territory, determined the Geographical distribution. We divided School size into three categories according to the number of students attending each high school as follows: small, $<200$; medium, 200 to 499 ; and large, $\geq 500$ and period of the day that students attended school in two categories: daytime and evening.

After, we selected the required sample performing a two-stage cluster sampling procedure. In the first stage, there was the stratification of schools by the school district. In the second stage, there was the stratification by class size and period of the day. We randomized participants using SPSS/PASW version 20 (IBM Corp, NY, USA), and the sampling unit for the final stage of the process was the class. All of these procedures to determine the sample have been described previously by Magalhães et al. ${ }^{18}$.

\section{Data collection}

Data collection was performed between May and October in 2011 during the period of the day that the adolescents were in class (morning, afternoon and evening). Socioeconomic and demographic characteristics were obtained using an adapted version of the Global School-based Student Health Survey ${ }^{19}$. Also, we performed the blood pressure evaluation and anthropometry. 


\section{High Blood pressure}

Blood pressure was measured using the Omron HEM 742 (Omron Corporation, Kyoto, Kansai, Japan $)^{20}$ after the adolescents rested and remained seated with legs uncrossed for $5 \mathrm{~min}$ utes. We used the appropriate cuff size for each subject. All blood pressure measurements were performed three times on the right arm placed at heart level in a seated position, with the interval of 1 minute between the measures. We used the mean value of the last two measurements ${ }^{21}$. High blood pressure was defined as systolic and/ or diastolic blood pressure equal or higher than the reference sex, age, and height-specific $95^{\text {th }}$ percentile $^{22}$.

\section{Independent variables}

\section{Sedentary behaviors}

The predictors in the present study were components of time spent in sedentary behavior, including television viewing, playing video games, using the computer and non-screen activities (talking to friends, playing cards or dominoes, talking on the phone, driving, or as a passenger, reading or studying). The mean time spent in each of these behaviors (in a typical week) was asked separately for weekdays and weekends, assigning weight 5 to weekdays and weight 2 to weekends and dividing the result by 7 to obtain the mean time in minutes per day ${ }^{14}$. Screen entertainment time is the sum of the weighted mean screen time (television + video game + computer). Total time sitting was a sum of screen entertainment and time sitting in other activities (talking to friends, playing cards or dominoes, talking on the phone, driving, or as a passenger, reading or studying). We followed given that the American Academy of Pediatrics ${ }^{23}$ recommendation and categorized all sedentary behavior in three groups: less than 2 hours per day, 2 to 4 hours and more than 4 hours per day of exposure.

Reproducibility indicators (i.e., test-retest consistency, one-week apart) showed the Spearman's rank correlation coefficient of 0.60 (weekdays) and 0.78 (weekends) for television viewing, 0.62 (weekdays) and 0.78 (weekends) for using the computer or video games and 0.42 (weekdays) and 0.56 (weekends) for non-screen activities.

\section{Confounders}

\section{Physical activity}

The participants reported their level of physical activity answering the questions: 'During the past week, how many days were you did exercise with a duration of 60 minutes or more?' and, 'During a typical week, how many days you did exercise with a duration of 60 minutes or more?' The average of both questions was considered to determine the level of physical activity. We classified the participants as physically active (threshold of five or more days per week with at least 60 minutes per day of moderate to vigorous physical activity) or insufficiently active ${ }^{24}$.

\section{Anthropometric variables}

We weighed the adolescents without shoes and coats on an electronic scale (model Sport), and the height was measured using a stadiometer. Overweight was determined by body mass index above the $85^{\text {th }}$ percentile for their sex and age according Cole et al. ${ }^{25}$.

\section{Sociodemographic variables}

Sociodemographic variables were gender), age, race, place of residence (Urban and Rural), occupation (work and not work), maternal education ( $\leq$ eight years of study and $>8$ years of study) were obtained.

\section{Statistical analysis}

Data entry was conducted using the EpiData software package. Electronic data control was ensured using the 'CHECK' function. We repeated the data entry and corrected the errors using the duplicate file comparison function. Data analysis was conducted using Statistical Package for the Social Sciences for Windows.

Data analysis included descriptive statistics (frequency distribution) and measures of association (Pearson chi-square and binary logistic regression). Binary logistic regressions were carried out to analyze whether HBP has association with each sedentary behavior (television viewing time, playing video games, using the computer and non-screen activities). Thus, for each sedentary behavior we conducted a regression model, and adjusted for physical activity level, status weight and other confounders variables $(\mathrm{p}<0.20$ in bivariate analyses), all being introduced simultaneously. We also performed the tests for interaction effects and the results are shown as crude and adjusted odds ratio (OR) values and 95\% con- 
fidence intervals (CIs). The Hosmer-Lemeshow test was used to assess the model goodness-of-fit.

\section{Results}

The research group visited eighty-five schools in 48 cities in the State of Pernambuco (in the northeast region of Brazil). In the selected schools, we interview a total of 7,195 students, but 919 participants were out of the target age group ( $\leq 13$ or $\geq 20$ years), and 12 questionnaires had inconsistent data and incompleteness. Thus, the total sample has 6,264 adolescents $(59.7 \%$ girls) adolescents with a mean age of $16.6 \pm 1.2$ years. Table 1 present the sociodemographic characteristics of the study group.

The prevalence of adolescents classified as insufficiently active was higher in girls $(\mathrm{p}<0.001)$. Overweight was present in $16.5 \%$ of the partici- pant and was similar between sexes. Girls spent more time on television viewing and sitting time except entertainment screen time, while boys spent more time on video games and computers and presented a higher total time sitting $(\mathrm{p}<$ 0.05) (Table 2).

Tables 3 and 4 show associations between sedentary behaviors and demographic data in boys and girls, respectively.

There was an interaction between sexes and sedentary behaviors $(\mathrm{p}<0.001)$; therefore, regression analyses were performed separately for sex (Table 5). The crude analysis showed that in television viewing time was positively associated with high blood pressure, only in boys. This association remained significant after adjustment for physical activity level, overweight, place of residence and educational level of the mother. There was a linear increase in the prevalence of HBP with television viewing time in boys; $<2$ hours

Table 1. Study participants' demographic and socioeconomic characteristics by sex.

\begin{tabular}{|c|c|c|c|c|c|c|c|}
\hline \multirow[t]{2}{*}{ Variable } & \multicolumn{2}{|c|}{$\begin{array}{c}\text { Boys } \\
(n=2524)\end{array}$} & \multicolumn{2}{|c|}{$\begin{array}{c}\text { Girls } \\
(\mathbf{n}=3737)\end{array}$} & \multicolumn{2}{|c|}{$\begin{array}{c}\text { Total } \\
(n=6264)\end{array}$} & \multirow[t]{2}{*}{ p-value } \\
\hline & $\mathbf{n}$ & $\%$ & $\mathbf{n}$ & $\%$ & $\mathbf{n}$ & $\%$ & \\
\hline Age group (years old) & & & & & & & $<0.001^{\star}$ \\
\hline 14 to 15 & 460 & 34.1 & 890 & 65.9 & 1350 & 21.6 & \\
\hline 16 to 17 & 1353 & 40.5 & 1991 & 59.5 & 3344 & 53.4 & \\
\hline 18 to 19 & 711 & 45.4 & 856 & 54.6 & 1567 & 25.0 & \\
\hline Employment status & & & & & & & $<0.001$ \\
\hline Yes & 804 & 57.9 & 584 & 42.1 & 1388 & 22.2 & \\
\hline No & 1713 & 35.3 & 3143 & 64.7 & 4856 & 77.8 & \\
\hline Television at home & & & & & & & 0.189 \\
\hline Yes & 2494 & 40.4 & 3678 & 59.6 & 6175 & 98.7 & \\
\hline No & 28 & 33.3 & 56 & 66.7 & 84 & 1.3 & \\
\hline Compute at home & & & & & & & $<0.001$ \\
\hline Yes & 1177 & 45.8 & 1394 & 54.2 & 2571 & 41.1 & \\
\hline No & 1343 & 36.5 & 2340 & 63.5 & 3686 & 58.9 & \\
\hline Computer with internet at home & & & & & & & $<0.001$ \\
\hline Yes & 984 & 46.0 & 1157 & 54.0 & 2141 & 34.3 & \\
\hline No & 1531 & 37.3 & 2573 & 62.7 & 4107 & 67.7 & \\
\hline Ethnicity & & & & & & & 0.411 \\
\hline White & 667 & 41.2 & 953 & 59.8 & 1620 & 26.0 & \\
\hline Nonwhite & 1848 & 39.0 & 2771 & 59.0 & 4619 & 74.0 & \\
\hline Place of residence & & & & & & & 0.938 \\
\hline Urban & 1878 & 39.4 & 2766 & 58.6 & 4644 & 74.5 & \\
\hline Rural & 640 & 39.3 & 947 & 58.7 & 1587 & 25.5 & \\
\hline Maternal education & & & & & & & $<0.001$ \\
\hline$\leq 8$ years of study & 1324 & 38.0 & 2164 & 62.0 & 3488 & 64.7 & \\
\hline$>8$ years of study & 864 & 44.4 & 1039 & 53.6 & 1903 & 35.3 & \\
\hline
\end{tabular}

* Test for linear trend. 
Table 2. High blood pressure, physical activity level, body mass index and sedentary behaviors by sex.

\begin{tabular}{|c|c|c|c|c|c|c|c|}
\hline \multirow[t]{2}{*}{ Variables } & \multicolumn{2}{|c|}{$\begin{array}{c}\text { Boys } \\
(\mathrm{n}=2524) \\
\end{array}$} & \multicolumn{2}{|c|}{$\begin{array}{c}\text { Girls } \\
(\mathrm{n}=3737)\end{array}$} & \multicolumn{2}{|c|}{$\begin{array}{c}\text { Total } \\
(n=6264)\end{array}$} & \multirow[t]{2}{*}{ p-value } \\
\hline & $\mathbf{n}$ & $\%$ & $\mathbf{n}$ & $\%$ & $\mathbf{n}$ & $\%$ & \\
\hline High blood pressure & & & & & & & $<0.001$ \\
\hline Yes & 251 & 10.4 & 191 & 5.2 & 442 & 7.3 & \\
\hline No & 2169 & 89.6 & 3464 & 94.8 & 5633 & 92.7 & \\
\hline Physical activity level & & & & & & & $<0.001$ \\
\hline Active & 1103 & 43.9 & 1088 & 29.2 & 2191 & 35.1 & \\
\hline Insufficient activity & 1411 & 56.1 & 2634 & 70.8 & 4045 & 64.9 & \\
\hline Status weight & & & & & & & $0.918^{\star}$ \\
\hline Eutrophic & 2034 & 84.1 & 3038 & 83.1 & 5072 & 83.5 & \\
\hline Overweight & 264 & 10.9 & 478 & 13.1 & 742 & 12.2 & \\
\hline Obesity & 121 & 5.0 & 141 & 3.9 & 262 & 4.3 & \\
\hline Television viewing & & & & & & & $0.024^{\star}$ \\
\hline$<2$ hours & 1231 & 48.9 & 1727 & 46.4 & 2958 & 47.4 & \\
\hline 2 to 4 hours & 977 & 38.8 & 1482 & 39.8 & 2459 & 39.4 & \\
\hline$>4$ hours & 310 & 12.3 & 516 & 13.9 & 826 & 13.2 & \\
\hline Playing video games and/or using the computer & & & & & & & $<0.001^{\star}$ \\
\hline$<2$ hours & 1482 & 58.9 & 2769 & 74.4 & 4251 & 68.1 & \\
\hline 2 to 4 hours & 714 & 28.4 & 679 & 18.2 & 1393 & 22.3 & \\
\hline$>4$ hours & 320 & 12.7 & 276 & 7.4 & 596 & 9.6 & \\
\hline Non-screen activities & & & & & & & $0.016^{*}$ \\
\hline$<2$ hours & 1162 & 46.7 & 1627 & 44.0 & 2789 & 45.1 & \\
\hline 2 to 4 hours & 988 & 39.7 & 1506 & 40.7 & 2494 & 40.3 & \\
\hline$>4$ hours & 339 & 13.6 & 568 & 15.3 & 907 & 14.7 & \\
\hline Total time sitting & & & & & & & $0.002^{\star}$ \\
\hline$<2$ hours & 218 & 8.8 & 395 & 10.7 & 613 & 9.9 & \\
\hline 2 to 4 hours & 509 & 20.5 & 815 & 22.1 & 1324 & 21.5 & \\
\hline$>4$ hours & 1750 & 70.6 & 2474 & 67.2 & 4224 & 68.6 & \\
\hline
\end{tabular}

${ }^{\star}$ Test for linear trend.

for television viewing time (prevalence of $\mathrm{HBP}=$ $8.5 \%), 2-4$ hours $(11.0 \%)$ and $>4$ hours $(15.8 \%)$; $(\mathrm{p}<0.001)$. For girls, we do not found associations between the different types of sedentary behaviors and HBP prevalence.

\section{Discussion}

The main findings of this study were: 1) girls spent more time on television viewing and nonscreen activities, whereas boys spent more time on video games and computers; 2) television viewing time have an association with HBP only in male group; 3) we don't found association between sedentary behaviors and HBP in girls.

The prevalence of adolescents who spent $>$ 4 hours per day viewing television and playing video games and/or using computers were lower than observed in previous studies in developed countries $^{14,26,27}$, and are probably explained by the lower income of our sample ${ }^{14,26}$. In fact, $58.9 \%$ of the adolescents did not have a computer, and $65.7 \%$ did not have internet access contributing to this lower prevalence when compared with other studies. In the analysis of sedentary behaviors stratified by sex, we observed that girls spent more time on television viewing and non-screen activities. However, other studies noted that boys (adolescents ${ }^{14}$ and children ${ }^{6}$ ) spent more time on video games, computers and sitting. This result reflects the entertainment preferences differences between sex.

Our study has shown that the positive association between television viewing time and HBP in boys even after adjustments. This find is in agreement with previous studies that showed a positive association between systolic blood pressure and television viewing time in children ${ }^{6}$, which was also observed in and adolescents ${ }^{28}$. In 


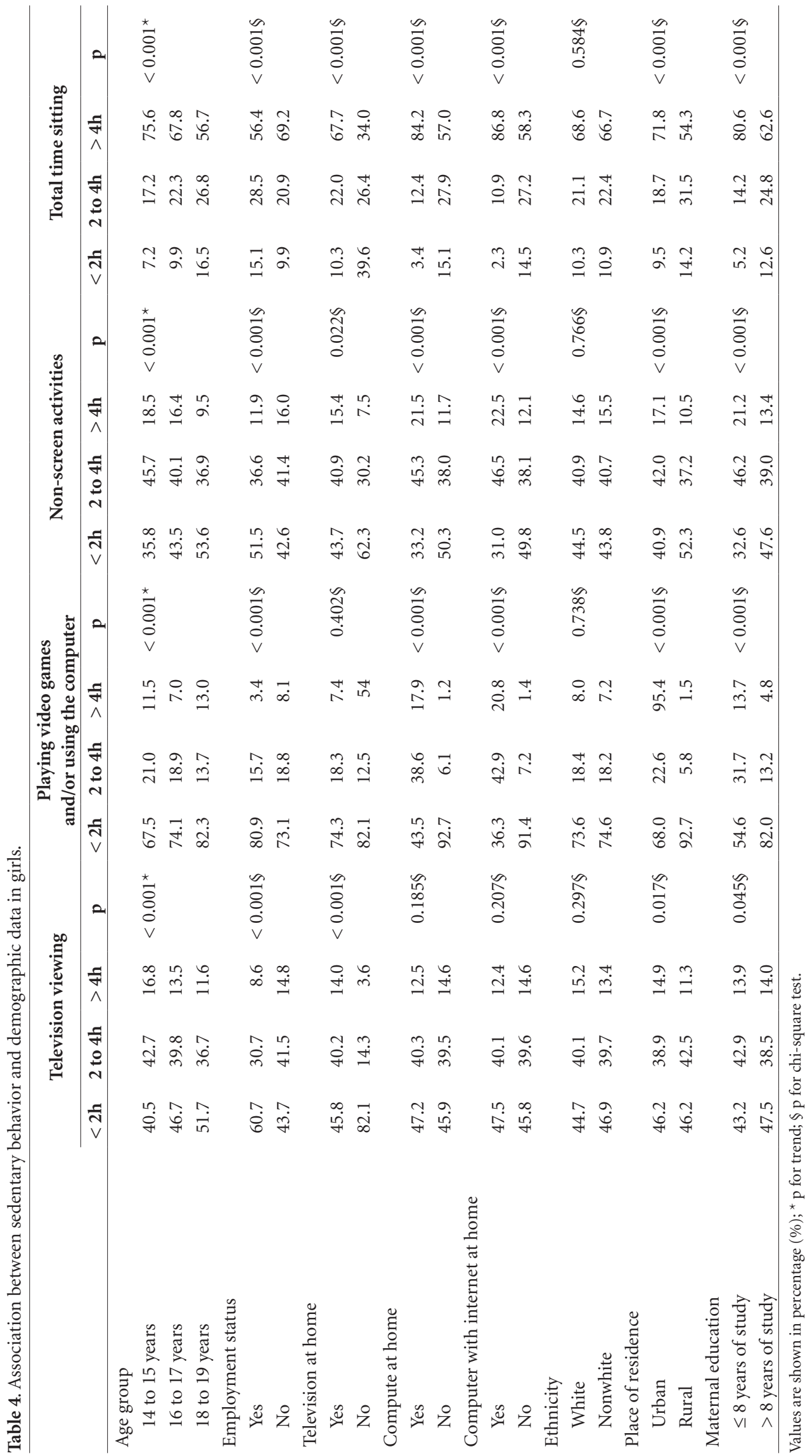


Table 5. Crude and adjusted odds ratios (OR) and confidence interval (CI 95\%) for the association between high blood pressure and different sedentary behaviors in boys and girls.

\begin{tabular}{|c|c|c|c|c|}
\hline & \multicolumn{2}{|c|}{ High blood pressure in boys } & \multicolumn{2}{|c|}{ High blood pressure in girls } \\
\hline & $\begin{array}{c}\text { Crude OR } \\
(\mathrm{CI} 95 \%)\end{array}$ & $\begin{array}{c}\text { Adjusted OR } \\
(\text { CI 95\%) }\end{array}$ & $\begin{array}{r}\text { Crude OR } \\
(\mathrm{CI} 95 \%)\end{array}$ & $\begin{array}{c}\text { Adjusted OR } \\
\text { (CI 95\%) }\end{array}$ \\
\hline \multicolumn{5}{|c|}{ Television viewing\# } \\
\hline$<2$ hours & 1 & 1 & 1 & 1 \\
\hline 2 to 4 hours & $1.34(1.00-1.79)$ & $1.34(0.99-1.81)$ & $1.24(0.91-1.70)$ & $1.07(0.75-1.52)$ \\
\hline$>4$ hours & $2.02(1.39-2.93)$ & $2.01(1.37-2.98)$ & $1.14(0.73-1.79)$ & $0.76(0.44-1.29)$ \\
\hline \multicolumn{5}{|c|}{ Playing video games and/or using the computer $\dagger$} \\
\hline$<2$ hours & 1 & 1 & 1 & 1 \\
\hline 2 to 4 hours & $0.82(0.60-1.13)$ & $0.97(0.66-1.43)$ & $0.92(0.63-1.36)$ & $1.05(0.62-1.76)$ \\
\hline$>4$ hours & $1.21(0.82-1.76)$ & $1.16(0.70-1.92)$ & $0.82(0.45-1.49)$ & $0.77(0.34-1.70)$ \\
\hline \multicolumn{5}{|c|}{ Non-screen activities $\S$} \\
\hline$<2$ hours & 1 & 1 & 1 & 1 \\
\hline 2 to 4 hours & $1.14(0.86-1.51)$ & $1.10(0.79-1.53)$ & $1.10(0.80-1.51)$ & $1.11(0.76-1.61)$ \\
\hline$>4$ hours & $0.95(0.62-1.44)$ & $1.00(0.62-1.61)$ & $1.06(0.69-1.64)$ & $1.14(0.70-1.86)$ \\
\hline \multicolumn{5}{|c|}{ Total time sitting } \\
\hline$<2$ hours & 1 & 1 & 1 & 1 \\
\hline 2 to 4 hours & $0.92(0.54-1.55)$ & $1.32(0.77-2.26)$ & $2.37(1.22-4.60)$ & $1.90(0.90-4.01)$ \\
\hline$>4$ hours & $0.97(0.61-1.54)$ & $0.85(0.56-1.26)$ & $1.91(1.02-3.56)$ & $1.46(0.71-2.96)$ \\
\hline \multicolumn{5}{|c|}{$\begin{array}{l}\text { \# Boys: Adjusted for physical activity level, status weight, TV at home age and employment status; Hosmer-Lemeshow test } \\
\text { ( } \mathrm{p}=0.913) ; \text {;irls: Adjusted for physical activity level, status weight, TV and computer at home, placed of residence, age, maternal } \\
\text { education, and employment status. Hosmer-Lemeshow test }(\mathrm{p}=0.592) \text {. } \dagger \text { Boys and Girls: Adjusted for physical activity level, status } \\
\text { weight, compute at home, compute at home with internet, maternal education, age and employment status; Hosmer-Lemeshow } \\
\text { test for boys }(\mathrm{p}=0.867) \text { and girls }(\mathrm{p}=0.758) \text {. } \$ \text { Boys and Girls: Adjusted for physical activity level, status weight, TV and compute } \\
\text { at home, compute at home with internet, maternal education, age and employment status; Hosmer-Lemeshow test for boys }(\mathrm{p}= \\
0.050) \text { and girls }(\mathrm{p}=0.755) \text {. } \ddagger \text { Boys: Adjusted for physical activity level, status weight, compute at home, compute at home with } \\
\text { internet, maternal education, age and employment status; Hosmer-Lemeshow test for boys }(\mathrm{p}=0.527) ; \text { Girls: Adjusted for physical } \\
\text { activity level, status weight, compute at home, compute at home with internet, ethnicity, maternal education, age and employment } \\
\text { status; Hosmer-Lemeshow test }(\mathrm{p}=0.332) \text {. }\end{array}$} \\
\hline
\end{tabular}

a recent survey of adolescents in Southern Brazil, authors noted that high sedentary behavior (TV + computer + video game) have an association with $\mathrm{HBP}^{29}$. However, in this other study, sex was used as an adjustment variable, while these relationships were explored stratifying up the sex in the present study. The mechanisms linking television viewing and HBP are not clear, and may be related to higher food consumption during TV watching, such as processed meat, soda, and candies that have high amounts of sodium, sugar, and caffeine during watching ${ }^{30,31}$. A previous study demonstrated that boys are more susceptible to food cues in commercials than girls ${ }^{32}$. In this study, boys consumed fewer vegetables, fruits, and natural juices than girls, which corroborate partially with this hypothesis.
We analyzed the association between the time playing video games, using the computer and the non-screen activities with HBP in adolescents and we do not found an association in both sexes. One possible reason is that the use of video games, in particular for sports games, can encourage a more active behavior. Another factor is that when played actively by the actives video games can occur improvements in cardiovascular parameters ${ }^{33}$.

Regarding the sitting time, there was a high prevalence of higher sitting time to 4 hours a day in both normotensive adolescents as in with high blood pressure which may have contributed to the observed association in this variable. However, this study did not evaluate the breakdown of sedentary behavior, which is a relevant limitation 
since this information has been associated with the decrease of blood pressure ${ }^{34}$.

In practical terms, our data support the American Academy of Pediatrics ${ }^{23}$ recommendation that parents should limit children's viewing TV to $1-2 \mathrm{~h}$ per day. Therefore, developing strategies those are effective in reducing time spent in television watching may be a determining factor for effectiveness of interventions aimed at lowering blood pressure, especially in adolescent boys, due to reduced exposure to advertisements that often promote unhealthy dietary habits. Furthermore, the previous studies ${ }^{35,36}$ have shown that take a short break in sitting time reduces the negative effects of sedentary behaviors in adolescents. On the other hand, for girls, other factors should be considered to reduce blood pressure instead of sedentary behavior.

The representative sample size and the fairly narrow age range are the study's strengths. Also, strict sampling procedures were established to ensure that the sample was representative of a Brazilian state population. The evaluation of different sedentary behaviors and the control for various potential confounders has also forced this study. There are also certain limitations that need to be pointed out. The cross-sectional design and the correlative nature of the data preclude us from establishing a causal relationship between HBP and sedentary behavior. Another factor is that blood pressure was assessed in a single day, which overestimates the proportion of adolescents with HBP. The use of self-reported measures of sedentary behavior and physical activity is an important limitation that needs to be considered. However, sedentary behavior questionnaires have been widely used, and they have advantages over accelerometer, such as low cost and the possibility of analyzing different sedentary behaviors.

In conclusion, the results of this study indicate that, in a large representative sample, only television viewing time was associated with HBP in boys, while the female group there was no association between the different types of sedentary behavior and HBP.

\section{Collaborations}

LMFT Oliveira, RM Ritti-Dias, BQ Farah, DGD Chirstofaro, MVG Barros, PRB Diniz and FJSP Guimarães participated equally in all stages of preparation of the article.

\section{Acknowledgments}

This work was supported by a grant from the Brazilian National Council for Scientific and Technological Development (CNPq). Brazilian Federal Agency for Support and Evaluation of Graduate Education (CAPES) provided an additional support, and the Foundation for Science and Technology of the State of Pernambuco (FACEPE). 


\section{References}

1. Lawes CM, Vander Hoorn S, Rodgers A. Global burden of blood-pressure-related disease, 2001. Lancet 2008; 371(9623):1513-1518.

2. Magalhaes MG, Oliveira LM, Christofaro DG, Ritti-Dias RM. Prevalence of high blood pressure in Brazilian adolescents and quality of the employed methodological procedures: systematic review. Rev Bras Epidemiol 2013; 16(4):849-859.

3. Urbina E, Alpert B, Flynn J, Hayman L, Harshfield GA, Jacobson M, Mahoney L, McCrindle B, Mietus-Snyder M, Steinberger J, Daniels S; American Heart Association Atherosclerosis, Hypertension, and Obesity in Youth Committee.. Ambulatory blood pressure monitoring in children and adolescents: recommendations for standard assessment a scientific statement from the American Heart Association Atherosclerosis, Hypertension, and Obesity in Youth Committee of the council on cardiovascular disease in the young and the council for high blood pressure research. Hypertension 2008; 52(3):433-451.

4. Franks PW, Hanson RL, Knowler WC, Sievers ML, Bennett PH, Looker HC. Childhood obesity, other cardiovascular risk factors, and premature death. $N \mathrm{Engl} \mathrm{J}$ Med 2010; 362(6):485-493.

5. Network SBR. Letter to the editor: standardized Use of the terms "sedentary" and "sedentary behaviours". Appl Physiol Nutr Metab 2012; 37(3):540-542.

6. Knuth AG, Malta DC, Dumith SC, Pereira CA, Morais Neto OL, Temporão JG, Penna G, Hallal PC. Practice of physical activity and sedentarism among Brazilians: results of the National Household Sample Survey--2008. Cien Saude Colet 2011; 16(9):3697-3705.

7. Moraes AC, Carvalho HB, Siani A, Barba G, Veidebaum T, Tornaritis M, Molnar D, Ahrens W, Wirsik N, De Henauw S, Mårild S, Lissner L, Konstabel K, Pitsiladis Y, Moreno LA; IDEFICS consortium. Incidence of high blood pressure in children - effects of physical activity and sedentary behaviors: the IDEFICS study: High blood pressure, lifestyle and children. Int J Cardiol 2015; 180:165-170.

8. Hardy LL, Denney-Wilson E, Thrift AP, Okely AD, Baur LA. Screen time and metabolic risk factors among adolescents. Arch Pediatr Adolesc Med 2010; 164(7):643649.

9. Altenburg TM, Hofsteenge GH, Weijs PJ, Delemarre-van de Waal HA, Chinapaw MJ. Self-reported screen time and cardiometabolic risk in obese Dutch adolescents. PloS One 2012; 7(12):e53333.

10. Tremblay MS, LeBlanc AG, Kho ME, Saunders TJ, Larouche R, Colley RC, Goldfield G, Connor Gorber S.. Systematic review of sedentary behaviour and health indicators in school-aged children and youth. Int $\mathrm{J} \mathrm{Be}$ hav Nutr Phys Act 2011;8:98.

11. Alamian A, Paradis G. Clustering of chronic disease behavioral risk factors in Canadian children and adolescents. Prev Med 2009; 48(5):493-499.

12. Colley RC, Garriguet D, Janssen I, Wong SL, Saunders TJ, Carson V, Tremblay MS. The association between accelerometer-measured patterns of sedentary time and health risk in children and youth: results from the Canadian Health Measures Survey. BMC Public Health 2013; 13:200.
13. Nelson MC, Neumark-Stzainer D, Hannan PJ, Sirard JR, Story M. Longitudinal and secular trends in physical activity and sedentary behavior during adolescence. Pediatrics 2006; 118(6):e1627-1634.

14. Dumith SC, Hallal PC, Menezes AM, Araujo CL. Sedentary behavior in adolescents: the 11-year follow-up of the 1993 Pelotas (Brazil) birth cohort study. Cad Saude Publica 2010; 26(10):1928-1936.

15. Dasgupta K, O’Loughlin J, Chen S, Karp I, Paradis G, Tremblay J, Hamet P, Pilote L. Emergence of sex differences in prevalence of high systolic blood pressure: analysis of a longitudinal adolescent cohort. Circulation 2006; 114(24):2663-2670.

16. Christofaro DG, Ritti-Dias RM, Chiolero A, Fernandes RA, Casonatto J, Oliveira AR. Physical activity is inversely associated with high blood pressure independently of overweight in Brazilian adolescents. Scand J Med Sci Sports 2013; 23(3):317-322.

17. de Jong E, Visscher TL, HiraSing RA Heymans MW, Seidell JC, Renders CM. Association between TV viewing, computer use and overweight, determinants and competing activities of screen time in 4- to 13-year-old children. Int J Obes (Lond) 2013; 37(1):47-53.

18. Magalhães MGPA, Farah BQ, Barros MVG, Ritti-Dias RM. Previous blood pressure measurement and associated factors in student adolescents. Einstein (São Paulo) 2015; 13(3):381-387.

19. Centers for Disease Control and Prevention (CDC). Global School-based Student Health Survey (GSHS, 2004). [cited 2018 Jan 13]. Available from: http://www. cdc.gov/gshs/

20. Christofaro DG, Fernandes RA, Gerage AM, Alves MJ, Polito MD, Oliveira AR. Validation of the Omron HEM 742 blood pressure monitoring device in adolescents. Arq Bras Cardiol 2009; 92(1):10-15.

21. Cardiology Society of Brazilian, Hypertension Society of Brazilian, Company Brazilian Nephrology. VI Brazilian Guidelines on Hypertension. Arq Bras Cardiol 2010; 95(1 Supl.):1-51.

22. Falkner B, Daniels SR. Summary of the Fourth Report on the Diagnosis, Evaluation, and Treatment of High Blood Pressure in Children and Adolescents. Hypertension 2004; 44(4):387-388.

23. American Academy of Pediatrics. Children, adolescents, and television. Pediatrics 2001; 107(2):423-426.

24. Prochaska JJ, Sallis JF, Long B. A physical activity screening measure for use with adolescents in primary care. Arch Pediatr Adolesc Med 2001; 155(5):554-559.

25. Cole TJ, Bellizzi MC, Flegal KM, Dietz WH. Establishing a standard definition for child overweight and obesity worldwide: international survey. BMJ 2000; 320(7244):1240-1243.

26. Guedes DP, Souza MV, Ferreirinha JE, Silva AJ. Physical activity and determinants of sedentary behavior in Brazilian adolescents from an underdeveloped region. Percept Mot Skills 2012; 114(2):542-552.

27. Nogueira JA, Macedo da Costa TH. Gender differences in physical activity, sedentary behavior, and their relation to body composition in active Brazilian adolescents. J Phys Act Health 2009; 6(1):93-98. 
28. Wells JC, Hallal PC, Reichert FF, Menezes AM, Araújo CL, Victora CG. Sleep patterns and television viewing in relation to obesity and blood pressure: evidence from an adolescent Brazilian birth cohort. Int J Obes (Lond) 2008; 32(7):1042-1049.

29. Christofaro DG, De Andrade SM, Cardoso JR, Mesas AE, Codogno JS, Fernandes RA. High blood pressure and sedentary behavior in adolescents are associated even after controlling for confounding factors. Blood Pressure 2015; 24(5):317-323.

30. Camelo Ldo V, Rodrigues JF, Giatti L, Barreto SM. Sedentary leisure time and food consumption among Brazilian adolescents: the Brazilian National School-Based Adolescent Health Survey (PeNSE), 2009. Cad Saude Publica 2012; 28(11):2155-2162.

31. Wiecha JL, Peterson KE, Ludwig DS, Kim J, Sobol A, Gortmaker SL. When children eat what they watch: impact of television viewing on dietary intake in youth. Arch Pediatr Adolesc Med 2006; 160(4):436-442.

32. Anschutz DJ, Engels RC, Van Strien T. Side effects of television food commercials on concurrent nonadvertised sweet snack food intakes in young children. Am J Clin Nutr 2009 ; 89(5):1328-1333.

33. Murphy EC, Carson L, Neal W, Baylis C, Donley D, Yeater R. Effects of an exercise intervention using Dance Dance Revolution on endothelial function and other risk factors in overweight children. Int J Pediatr Obes 2009; 4(4):205-214.

34. Larsen R, Kingwell B, Sethi P, Cerin E, Owen N, Dunstan D. Breaking up prolonged sitting reduces resting blood pressure in overweight/obese adults. Nutr Metab Cardiovasc Dis 2014; 24(9):976-982.

35. Cliff DP, Jones RA, Burrows TL, Morgan PJ, Collins CE, Baur LA, Okely AD. Volumes and bouts of sedentary behavior and physical activity: associations with cardiometabolic health in obese children. Obesity 2014; 22(5):E112-118.

36. Saunders TJ, Tremblay MS, Mathieu MÈ, Henderson M, O'Loughlin J, Tremblay A, Chaput JP; QUALITY cohort research group. Associations of sedentary behavior, sedentary bouts and breaks in sedentary time with cardiometabolic risk in children with a family history of obesity. PloS One 2013; 8(11):e79143.

Artigo apresentado em 02/06/2016

Aprovado em 03/09/2016

Versão final apresentada em 05/09/2016 


\section{ERRATA}

p. 2575

onde se lê:

${ }^{3}$ Unidade de Tele Saúde, Hospital das Clínicas, Universidade Federal de Pernambuco. Recife PE Brasil.

leia-se:

${ }^{3}$ Departamento de Educação Física da Universidade Federal Rural de Pernambuco. Recife PE Brasil. 